\title{
Weight abnormalities among Nigerian women: correlates and programmatic implications.
}

\author{
Stella Babalola \\ Center for Communication Programs, Bloomberg School of Public Health \\ Johns Hopkins University, Baltimore, MD 21239, USA \\ stellababalola@jhu.edu
}

\begin{abstract}
Whereas overweight is on the rise among women in Africa, many African women are still underweight, introducing a dual burden for the countries' limited resources. Using data from the $2013 \mathrm{DHS}$, this paper examines this dual problem and its correlates in Nigeria. There is significant co-existence of overweight and underweight within the major socio-demographic groups. Nationally, more than twice as many women of reproductive age are overweight as are underweight (24.6 versus II.3\%). The factors positively associated with the risk of being overweight rather than having a normal weight include being ever-married, southern ethnic descent, higher education, higher wealth quintiles, prevalence of post-primary education in one's cluster, and urban residence. Programmatic efforts in Nigeria should target underweight and overweight by encouraging people to consume more wholesome meals, providing nutritional assistance for underweight women, addressing factors that favor weight abnormalities in the built environment and engaging communities in changing unhealthy norms related to nutrition.
\end{abstract}

Key words: obesity; overweight; underweight; Nigeria

\section{Introduction}

Underweight and overweight are two forms of the malnutrition problem. For reasons related to poverty, famine and endemic bacterial and parasitic diseases, Africa has traditionally been linked with a high prevalence of undernutrition (including underweight and micronutrient deficiencies that cut across all age groups (Müller and Krawinkel, 2005, Dickson et al., 2000). While undernutrition continues to be a serious problem in many African countries, there is increasing recognition that overnutrition and the attendant nutrition-related non-communicable diseases are on the rise in these countries (Benkeser et al., 2012, Keding et al., 2013, Ziraba et al., 2009, Diop et al., 20I4). The factors commonly adduced for the rise in overweight in African countries include globalization, urbanization and the attendant increased consumption of (often imported) highcaloric foods rich in sugars and saturated fats and reduced consumption of vegetables, whole grains and fruits (Witkowski, 2007, Popkin and Nielsen, 2003).

Many developing countries are now facing the dual burden of overweight and underweight. For example, in South Africa, Reddy et al. (2009) found that both underweight and overweight are common problems among teenagers. Similarly, Mendez et al. (2005) reported that overweight exceeded underweight in most of the 36 developing countries included in their study (Mendez et al., 2005). Another study found evidence of co-existence of obesity and undernutrition in Gambia, especially among middleage urban women (Van Der Sande et al., 200I).

The co-occurrence of underweight and overweight has introduced a double burden of malnutrition not only at the national level but also at the household level in many developing countries. The phenomenon of dual burden households in which underweight individuals live under the same roof with overweight persons is increasingly common in Africa (Bouzitou et al., 2005). At the national level, the co-occurrence of these two types of malnutrition further taxes the already strained and weakened national health infrastructure.

There is a dearth of studies on the factors associated with the dual problem of overweight and underweight in African countries. The present study is an attempt to bridge this knowledge gap. Using data from the 2013 Demographic and Health Survey in Nigeria, this study estimates the prevalence of underweight and overweight in women of reproductive age and compares the ratio of overweight to underweight across sociodemographic groups. The study also uses multinomial logit regression to assess factors associated with the relative risk of being overweight or underweight. 


\section{Literature Review}

Both overweight and underweight have serious implications for health and wellbeing of individuals and households. Overweight has been linked to multiple health problems, including liver and gallbladder disease, respiratory problems, osteoarthritis, abnormal menses, and infertility (Van Der Sande et al., 200I, Asfaw, 2006, Cappuccio et al., 2008, Udjo and Lalthapersad-Pillay, 2014). Overweight is also associated with increased risk of developing diabetes, cardiovascular diseases and even certain cancers (Smith et al., 2008, Cedergren, 2004, Krishnamoorthy et al., 2006). Furthermore, overweight (particularly obesity) during pregnancy has also been associated with higher probability of experiencing pregnancy-related complications, including caesarian delivery, postpartum infection, and preeclampsia (Smith et al., 2008, Weiss et al., 2004). Maternal overweight also has implications for the health of the baby and has been found to be associated with increased odds of low birth weight, prematurity, birth injury, fetal overweight, cardiovascular disease, childhood overweight, intrauterine death, and neonatal mortality (Smith et al., 2008, Weiss et al., 2004, Cresswell et al., 6 20I2, Boney et al., 2005, Callaway et al., 2006, BiderCanfield et al., 2016). Underweight in women has implications for the woman's ability to fight infections and recover from acute illness, her chances of developing osteoporosis, reduced productivity, and higher mortality (Black et al., 2008, Leslie, 1991, Rotimi et al., 1999). Maternal underweight during pregnancy has been found to be associated with increased odds of pregnancy-related complications and adverse pregnancy outcome, including antenatal anemia, fetal growth restrictions, low birth weight and prematurity (Black et al., 2008, Han et al., 20I I, Sebire et al., 200I).

The literature on the correlates of weight abnormalities has identified a number of factors that may increase a person's risk of underweight or overweight. For example, some studies have identified macro-economic conditions, poverty and low income as key factors underlying underweight among women (Müller and Krawinkel, 2005, Rotimi et al., 1999, Bharati et al., 2007). Other factors that have been found to be associated with underweight in adult women include older age, parity, low education, husband's low education, and rural residence (Rotimi et al., 1999, Bharati et al., 2007, Uthman and Aremu, 2008, Teller and Yimer, 2015). The factors negatively associated with underweight in literature have generally been found to be positively related to overweight. In essence, studies have found that the risk factors for being overweight include being female, rural residence, higher socio-economic status, a family history of overweight, low education, being married, physical inactivity, and sedentary lifestyle (Bouzitou et al., 2005, Bharati et al., 2007, Zargar et al., 2000, Kaplan et al., 2003). Other studies have emphasized the role of culture and particularly cultural norms regarding ideal body size and shape in determining actual body weight (Holdsworth et al., 2004, Cohen et al., 2013).

\section{Data and Methods}

\section{Population and Sample}

The data analyzed in this manuscript are publicly available and come from 2013 Nigeria Demographic and Health Surveys (DHS). The sampling design for the survey was such that fieldworkers selected eligible women through a stratified multi-stage procedure that involved first selecting clusters and then households within the clusters. More information about the sampling procedure is provided in the survey report available on the DHS Program website (http://www.dhsprogram.com).

The participants in this study are women aged 15 - 49 years. During the survey, the women's height and weight were measured using high precision equipment. In addition, the women were asked specific questions regarding their socio-demographic characteristics and household ownership of specific goods. The dataset contains information on 38948 women of reproductive age of whom 34455 were not pregnant at the time of the survey. Valid weight and height information was available for 33894 nonpregnant women; these women formed the basis of the analyses reported in this manuscript.

\section{Measures}

We analyze two dependent variables in this manuscript; each denotes one form of weight abnormality: overweight and underweight. Both measures are derived from the body mass index (BMI), defined as body weight in kilograms divided by the square of height in meters. The World Health Organization defines overweight as BMI between 25 $\mathrm{kg} / \mathrm{m}^{2}$ and $29.99 \mathrm{~kg} / \mathrm{m}^{2}$ and obesity as a BMI of 30 $\mathrm{kg} / \mathrm{m}^{2}$ or greater $(\mathrm{WHO}, 2000)$. For our first dependent variable, we combine these two categories and, for the sake of parsimony, refer to it in the rest of this manuscript as being overweight. The second dependent variable - underweight - is defined as a BMI less than $18.5 \mathrm{~kg} / \mathrm{m}^{2}$. Normal weight is defined as a BMI between $18.5 \mathrm{~kg} / \mathrm{m}^{2}$ and 24.99 $\mathrm{kg} / \mathrm{m}^{2}$.

Twelve independent variables were assessed (Table I). At the individual level, we assessed current age, marital status, religion, education, employment status, number of children-ever-born, autonomy, and 
ethnicity. At the household level, we assessed household wealth status.

The variables assessed at the community (cluster) level include type of place of residence (urban or rural), the proportion of women in the woman's cluster who have post-primary education, and media saturation in the woman's cluster. The choice of these independent variables was informed by what extant literature says regarding the factors associated with weight abnormalities, in particular, and health outcomes, in general, in African countries.

\begin{tabular}{|c|c|}
\hline Variable & Description and measurement \\
\hline 1. Marital Status & $\begin{array}{l}\text { Respondents were divided into three categories according: never married, currently married, and } \\
\text { divorce/separated/widowed }\end{array}$ \\
\hline 2. $\quad$ Religion & Defined as Christian, Moslem, or others. \\
\hline 3. Ethnicity & $\begin{array}{l}\text { We recognized the major ethnic groups: Fulani, Hausa, Igbo, Ijaw/Izon, and Yoruba. We then } \\
\text { classified the others into northern minorities or southern minorities. }\end{array}$ \\
\hline 4. $\quad$ Current age & Defined as age of the woman at last birthday, measured in single years. \\
\hline 5. $\quad$ Current employment status & Defined as currently employed or not. \\
\hline 6. Level of education & Defined as no education, primary, secondary or higher. \\
\hline 7. Woman's autonomy & $\begin{array}{l}\text { Defined as whether or not the woman participates in at least one key decision within the household, } \\
\text { including own health care, large household purchases and visits to family. }\end{array}$ \\
\hline $\begin{array}{l}\text { 8. Number of children had over } \\
\text { the last five years }\end{array}$ & We divided the women into three categories: no children, one child, and two children or more. \\
\hline 9. $\quad$ Household wealth & $\begin{array}{l}\text { An asset-based ordinal variable that classified women into five categories: poorest, poor, medium, } \\
\text { rich, and richest in the original dataset. }\end{array}$ \\
\hline 10. Type of place of residence & Defined as a binary variable distinguishing between urban and rural communities \\
\hline $\begin{array}{l}\text { 11. Proportion of women in } \\
\text { community with post-primary } \\
\text { education }\end{array}$ & $\begin{array}{l}\text { Derived from the non-self mean of women in the same cluster as the index woman who reported } \\
\text { post-primary education. The resulting variable classifies women into three categories based on the } \\
\text { prevalence of post-primary education in their cluster: low, medium and high. }\end{array}$ \\
\hline $\begin{array}{l}\text { 12. Media saturation in community } \\
\text { of residence }\end{array}$ & $\begin{array}{l}\text { Derived from the non-self mean level of exposure to the radio, newspaper and the television for the } \\
\text { women in the same cluster as the index woman. We divide the variable into three categories, viz.: } \\
\text { low, medium and high levels of community media saturation. }\end{array}$ \\
\hline
\end{tabular}

\section{Data Analysis}

We performed two types of analyses: comparison of the proportion overweight to the proportion underweight in each socio-demographic group and multinomial logit regression. To account for the design structure of DHS data, all the analyses are weighted using the inverse of the sampling probability. We start the analysis by comparing the ratio of overweight to underweight (ROU) across socio-demographic groups. A ROU less than I means that there are more underweight than overweight women in the specific group. If the ROU is more than $\mathrm{I}$, then there are more overweight individuals than underweight persons in that group. The multinomial logit regression assesses socio-demographic, household and community variables associated with the risk of being overweight or underweight rather than being of normal weight. This analytic approach allows us to explore the differences in the correlates of each health condition. All analyses were performed using Stata 13.

\section{Results}

Table 2 presents the socio-demographic characteristics of the sample. A little over one quarter of the respondents were never married while almost two- thirds were currently married. The majority of the women were currently employed and there are approximately equal proportions of Christians and Moslems. The majority of the women had some education, worked and did not participate in key household decisions. About half had at least one child during the last five years.

Table 2: Percent distribution of non-pregnant women with BMI data by selected background variables, Nigeria 2013

\begin{tabular}{llll} 
Background Variable & $\mathrm{N}$ & Unweighted $\%$ & Weighted $\%$ \\
\hline Marital Status & & & \\
Single & 9513 & 28.07 & 26.85 \\
Married/Cohabiting & 22609 & 66.71 & 68.08 \\
Div./Sep./Wid. & 1772 & 5.23 & 5.07 \\
\hline
\end{tabular}

Religion 


\begin{tabular}{|c|c|c|c|}
\hline Christian & 17886 & 52.77 & 48.63 \\
\hline Moslem & 15565 & 45.92 & 49.97 \\
\hline Other & 443 & 1.31 & 1.40 \\
\hline \multicolumn{4}{|l|}{ Ethnicity } \\
\hline Fulani & 1990 & 5.87 & 6.25 \\
\hline Hausa & 7767 & 22.92 & 26.33 \\
\hline Igbo & 4907 & 14.48 & 15.03 \\
\hline Ijaw/Izon & 1391 & 4.10 & 1.94 \\
\hline Yoruba & 5129 & 15.13 & 14.77 \\
\hline Northern Minority & 8386 & 24.74 & 23.36 \\
\hline Southern Minority & 4324 & 12.76 & 12.32 \\
\hline \multicolumn{4}{|l|}{ Age Group } \\
\hline $15-24$ & 12782 & 37.71 & 37.48 \\
\hline $25-34$ & 10179 & 30.03 & 30.60 \\
\hline $35+$ & 10933 & 22.26 & 31.92 \\
\hline \multicolumn{4}{|l|}{ Employment Status } \\
\hline Does not work & 13017 & 38.41 & 38.23 \\
\hline Works & 20877 & 61.59 & 61.77 \\
\hline \multicolumn{4}{|l|}{ Education Level } \\
\hline None & 11415 & 33.68 & 36.22 \\
\hline Primary & 6152 & 18.15 & 17.22 \\
\hline Secondary & 12948 & 38.20 & 36.94 \\
\hline Higher & 3379 & 9.97 & 9.63 \\
\hline \multicolumn{4}{|c|}{ Autonomy: Participation in household decisions } \\
\hline Does not participate & 21495 & 63.42 & 64.27 \\
\hline Participates & 12399 & 36.58 & 35.73 \\
\hline \multicolumn{4}{|c|}{ Number of children-ever-born } \\
\hline None & 10406 & 50.45 & 49.62 \\
\hline One & 6844 & 24.55 & 24.99 \\
\hline Two or more & 9107 & 25.00 & 25.38 \\
\hline \multicolumn{4}{|l|}{ Wealth quintile } \\
\hline Lowest & 5452 & 16.09 & 17.40 \\
\hline Second & 6352 & 18.74 & 18.45 \\
\hline Middle & 6992 & 20.63 & 19.30 \\
\hline Fourth & 7531 & 22.22 & 21.08 \\
\hline Highest & 7567 & 22.33 & 23.77 \\
\hline \multicolumn{4}{|c|}{ Type of place of residence } \\
\hline Rural & 20004 & 59.02 & 56.63 \\
\hline Urban & 13890 & 40.98 & 43.37 \\
\hline All Respondents & 33894 & 100.00 & 100.00 \\
\hline
\end{tabular}

The mean BMI is 22.95 ( $95 \% \mathrm{Cl}: 22.8 \mathrm{I}$ - 23.09). The data show that ROU varied considerably across Based on their BMI, fewer than two-thirds $(64.1 \%)$ groups. For example, whereas proportionally more of the women had a normal weight $1 \mathrm{I} .3$ percent never-married women were underweight than were were underweight and 24.6 percent were overweight, the reverse was the case among their overweight (including $7.4 \%$ who were obese). ever-married peers. Among ethnic groups,

\section{Bivariate Analyses}

Table 3 presents weight distribution by selected socio-demographic and other background variables. overweight was significantly more common than underweight among the lgbo, Yoruba, ljaw and other southern ethnic groups. In contrast, the Fulani of the north were more likely to be underweight than http://aps.journals.ac.za 
overweight whereas both overweight and underweight were equally likely among the Hausa. The relative prevalence of overweight compared to underweight increased with age, educational level, and wealth quintile. In addition, the relative prevalence of overweight compared to underweight was higher in urban than in rural areas and for women who participated in household decision compared to their peers who did not.

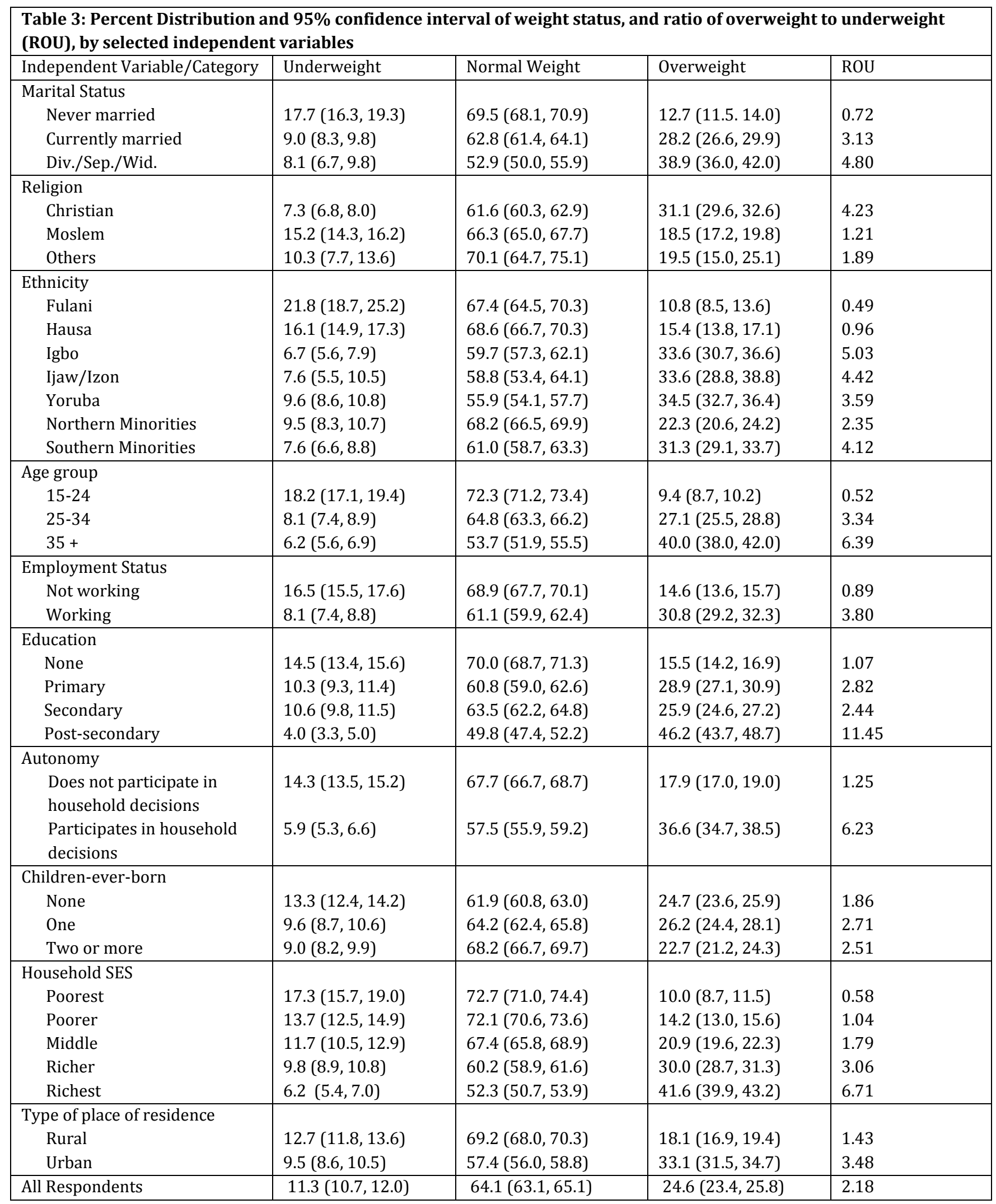

Using an arbitrary threshold of 10 percent to denote a significant burden of underweight or overweight, the groups most affected by the dual burden of overweight and underweight were unmarried 
women, the Fulani, the Hausa and unemployed women. Others include women with no education, rural women and poorer women.
The unadjusted associations presented above may be due to interrelationships among the independent variables. We therefore adjust for confounders in a multivariable, multinomial model and the results are presented in Table 4

\begin{tabular}{|c|c|c|}
\hline \multirow[t]{2}{*}{ Socio-demographic Characteristics } & \multicolumn{2}{|c|}{ Relative Risk Ratio } \\
\hline & $\begin{array}{c}\text { Underweight vs. Normal } \\
\text { Weight }\end{array}$ & Overweight vs. Normal Weight \\
\hline \multicolumn{3}{|l|}{ Marital Status } \\
\hline Single (RC) & 1.00 & 1.00 \\
\hline Married & $0.655^{* * *}$ & $1.731^{* * *}$ \\
\hline Div/Sep/Wid & 0.841 & $1.793^{* * *}$ \\
\hline \multicolumn{3}{|l|}{ Ethnicity } \\
\hline Fulani (RC) & 1.00 & 1.00 \\
\hline Hausa & $0.680^{* * *}$ & 1.173 \\
\hline Igbo & $0.473^{* * *}$ & 1.197 \\
\hline Ijaw/Izon & $0.406^{* * *}$ & $1.475^{* * *}$ \\
\hline Yoruba & $0.701^{* * *}$ & 0.967 \\
\hline Northern Minorities & $0.469^{* * *}$ & $1.343^{* * *}$ \\
\hline Southern Minorities & $0.536^{* * *}$ & $1.216^{*}$ \\
\hline \multicolumn{3}{|l|}{ Current Age } \\
\hline Age in years & $0.863^{* * *}$ & $1.272^{* * *}$ \\
\hline Square of age & $1.002^{* * *}$ & $0.997^{* * *}$ \\
\hline \multicolumn{3}{|l|}{ Employment Status } \\
\hline Not working (RC) & 1.00 & 1.00 \\
\hline Working & $0.832^{* * *}$ & $1.109^{* *}$ \\
\hline \multicolumn{3}{|l|}{ Education Level } \\
\hline No education (RC) & 1.00 & 1.00 \\
\hline Primary & 0.952 & $1.196^{* * *}$ \\
\hline Secondary & $0.691^{* * *}$ & $1.379 * * *$ \\
\hline Higher & $0.540^{* * *}$ & $1.826^{* * *}$ \\
\hline \multicolumn{3}{|l|}{ Autonomy } \\
\hline $\begin{array}{l}\text { Does not participate in any major household } \\
\text { decisions (RC) }\end{array}$ & 1.00 & 1.00 \\
\hline $\begin{array}{l}\text { Participates in at least one major household } \\
\text { decisions }\end{array}$ & $0.855^{* *}$ & 1.077 \\
\hline \multicolumn{3}{|l|}{ Children born in last 5 years } \\
\hline None (RC) & 1.00 & 1.00 \\
\hline One & 1.013 & $0.848^{* * *}$ \\
\hline Two or more & 0.888 & $0.826^{* * *}$ \\
\hline \multicolumn{3}{|l|}{ Household Wealth Quintile } \\
\hline Lowest (RC) & 1.00 & 1.00 \\
\hline Second & 0.946 & $1.362^{* * *}$ \\
\hline Middle & $0.869^{*}$ & $1.809^{* * *}$ \\
\hline Fourth & $0.814^{* *}$ & $2.527^{* * *}$ \\
\hline Highest & $0.680^{* * *}$ & $3.756^{* * *}$ \\
\hline
\end{tabular}

Type of place of residence 


\begin{tabular}{lll} 
Rural (RC) & 1.00 & 1.00 \\
Urban & $1.206^{* * *}$ & $1.125^{* * *}$ \\
\hline $\begin{array}{l}\text { Percent with post-primary education in cluster } \\
\text { Low (RC) }\end{array}$ & 1.00 & 1.00 \\
Medium & $0.788^{* * *}$ & $1.169^{* *}$ \\
High & $0.614^{* * *}$ & $1.165^{*}$ \\
\hline Media saturation in cluster of residence & 1.00 \\
Low (RC) & 1.00 & 1.060 \\
Medium & 1.047 & $1.215^{* * *}$ \\
High & 1.094 & $13.6 \%$ \\
\hline Pseudo- ${ }^{2}$ & & 33894 \\
\hline Number of Observations & & \\
\hline Notes: ${ }^{*} \mathrm{p}<0.05 ;{ }^{* *} \mathrm{p}<0.01 ;{ }^{* * *} \mathrm{p}<0.001$ & & \\
\hline
\end{tabular}

\section{Multivariable Analyses}

Underweight Relative to Normal Weight. The variables independently associated with the risk of being underweight include marital status, ethnicity, age, employment status, and education. Other relevant variables are the number of children in the last five years, wealth quintile, and urban residence. Keeping all other variables in the model constant, the relative risk of being underweight rather than being of normal weight was lower among the currently married compared to their never married peers. The risk of being underweight was also significantly lower for other ethnic groups compared to the Fulani. There was a curvilinear relationship with age such that the risk of underweight decreased initially with age and then increased thereafter; the inflection point was around 36.8 years. Furthermore, the relative risk for underweight was 17 percent lower for gainfully employed women than for their peers who were not working. The relationship with education was negative such that the relative risk for underweight rather than normal weight among women with higher education was almost half the corresponding risk among women with no education. The risk was about 15 percent lower among women who participate in at least one major household decisions compared to their peers who do not. The data further revealed that the relative risk for underweight decreased monotonically with wealth quintile and with the prevalence of post-primary education in the cluster of residence. In contrast, the relative risk of being underweight for urban women was 20 percent higher than the corresponding relative risk for their rural peers. The risk of being underweight was not significantly associated with the number of children born in the last five years or media saturation in the cluster of residence.

Overweight Relative to Normal Weight. With a couple of exceptions, the same variables that were associated with the risk of being underweight were also linked with the risk of being overweight. The relative risk of being overweight rather than having a normal weight was 73 percent higher for married women and 79 percent higher for previously married women compared to the corresponding risk for never married women. Regarding ethnicity, the risk for being overweight was 47 percent higher for ljaw/Izon, 34 percent higher for northern minorities, 34 percent higher for northern minorities and 21 percent higher among southern minorities compared to the Fulani. In contrast, the Yoruba were not significantly less likely than the Fulani to be overweight. The relationship with age reveals a concave pattern with initial increases with age following a gradual decrease starting from around age 44. Working women are II percent more likely to be overweight than the unemployed while urban women were about 13 percent more likely to be overweight compared to rural women. The relationship with the number of children born during the last five years was unexpectedly negative. Furthermore, the risk of being overweight increases monotonically with education and wealth quintile. Similarly, living in a cluster with a higher prevalence of post-12 primary education or with a higher prevalence of media saturation was associated with higher risk of being overweight. Women's autonomy did not appear to be significantly associated with overweight.

\section{Discussion}

Using the 2013 DHS data, this paper examined the role of individual, household, measured community compositional, and contextual factors in determining the prevalence of weight abnormalities in Nigeria. The study found a high prevalence of both underweight and overweight among the study population. Nationally, overweight was twice as 
prevalent as underweight. This finding is indicative of a dual burden of malnutrition and consistent with the results of other studies in Africa (Reddy et al., 2009, Van Der Sande et al., 200I).

Consistent with the findings of Reddy and colleagues in South Africa, the dual burden of underweight and overweight affects some groups more than others in Nigeria (Reddy et al., 2009). For example, among the Fulani, unmarried women, young women aged less than 25 years old, and the poorest women, underweight significantly exceeds overweight. At the same time, the proportion overweight was non-negligible among these groups. Among the Hausa, women with no education, and women in the second wealth quintile, there are roughly as many overweight as underweight women. In contrast, overweight significantly exceeds underweight among most other socio-demographic groups, including married, older, educated, autonomous, richer, and southern women. The coexistence of overweight and underweight may put considerable strain on available limited funds for disease prevention, management and care.

The multivariable analyses reveal that the risk of overweight initially increased with age until around the age of 44 years. The positive relationship of age with overweight has been found in 13 many settings (Bharati et al., 2007, Uthman, 2009). The finding underscores the need to target women with weight control interventions early in the reproductive years before weight accumulation becomes problematic. At the same time, the finding that the risk of underweight was higher for younger women indicates that weight control messages and programmatic efforts should not just focus on underweight or overweight control but should emphasize the need for maintaining healthy weight through appropriate nutrition and healthy lifestyles across all age groups. The variations in the risks of underweight and overweight by ethnicity reflect the multicultural nature of the Nigerian society and differences in dietary patterns (Adegboye et al., 2015). The finding that the relative risk of underweight was lower among all other ethnic groups compared to the Fulani is consistent with what other studies have found (Kandala and Emina, 2016, Glew et al., 2004, Bello et al., 2016). One explanation for the higher prevalence of underweight among the Fulani might be their relatively lower energy intake coupled with more active lifestyles (Lindsay et al., 20I2, Glew et al., 200 I)

The positive association of employment with overweight points to the relevance of workplace initiatives aimed at educating women on healthy diets and lifestyles. Another finding that supports the need for workplace initiatives is the positive association of education with overweight. Such initiatives should be culturally relevant, based on empirical data and could use existing women networks and associations in the workplace to reach women with appropriate messages on health-protective food choices and provide a forum for them to exercise together. Workplace interventions addressing both underweight and overweight have been implemented with success in some African countries (Doak, 2002, Milner et al., 20I5).

The present study found that there are significant wealth inequalities in overweight that are independent of individual characteristics of the woman. This finding is not surprising and is consistent with what other studies have found (Uthman, 2009, Fezeu et al., 2006). The finding that women in the second wealth quintile are significantly more likely to be overweight than their peers in the first quintile indicates that overweight may be becoming generalized among Nigerian women, cutting across socio-economic class. One study has found that overweight is spreading faster among the poor than among the rich in African countries (Ziraba et al., 2009).

Urban residence is positively associated with higher risk of overweight. This finding is consistent with what several studies have found in African countries and elsewhere (Ziraba et al., 2009, Uthman and Aremu, 2008). Indeed, it makes sense to expect that sedentary lifestyles and increased westernization of diets, characterized by consumption of imported foods and drinks that are rich in energy and saturated fats will make for higher prevalence of overweight in urban areas (Popkin and Nielsen, 2003, Schmidhuber and Shetty, 2005). Urban residence was also associated with increased risk of underweight compared to rural residence. This finding was unexpected but points to the presence of greater inequality in urban than in rural areas.

The negative association of recent parity and overweight is surprising and inconsistent with what some studies have found (Wen et al., 2003, Ziraba et al., 2009, Lopez-Arana et al., 2013). There are at least two possible explanations for this curious finding. First, it stands to reason that repeated childbearing leads to maternal depletion and fosters weight loss (Merchant and Martorell, 1987). It is reasonable to argue that the negative association between repeated childbearing and maternal depletion will be stronger in settings where poverty is widespread and food security constitutes a challenge. Indeed, one study based on secondary analysis of DHS data from 50 countries found that the relationship between parity and overweight was dependent on the level of economic development in the country (Kim et al., 2007a). Specifically, the study 
found that the strength of the positive association between parity and the risk of overweight increased with the country GDP. Another multi-country comparative analysis based on the DHS found that the positive association of parity to overweight was a function of household wealth and country development (Kim et al., 2007b). The study found a negative relationship between parity and overweight among poor women living in the lowest Human Development Index (HDI) countries. Second, some studies have documented the negative link between overweight/obesity and fecundity (Yilmaz et al., 2009, Moragianni et al., 2012, van der Steeg et al., 2008). In other words, a negative link between overweight and fecundity may explain why women who had more children in the last five years were less likely than those who had no child to be overweight.

This study has some limitations that should be highlighted. For example, the limitations of BMI as a surrogate measure for body fat has been eloquently discussed elsewhere (Prentice and Jebb, 200I). BMI is based on body weight and height. It does not take muscle distribution and bone mass into consideration. More important, what makes obesity and overweight problematic is the associated excess accumulation of body fat (adipose tissue), not the excess weight. There is credible evidence that BMI may provide misleading results for the elderly, non-Caucasians, people with small frame, and people with high muscular mass such as athletes and military personnel (World Health Organization, 2000, Romero-Corral et al., 2008). In addition, although BMI has been found to have high specificity, it has been shown to have low to moderate sensitivity for identifying cases of body fat-defined obesity or thinness (Gartner et al., 2000). Nonetheless, BMI is easy to calculate and available for national populations in developing countries through surveys such as the DHS.

Another limitation of this study is that the data analyzed derive from household survey. Whereas the components required for computing the BMI (height and weight) were scientifically measured and therefore potentially objective, the correlates included in our analyses were self-reported and therefore subject to recall and social desirability bias. In addition, the cross-sectional nature of the survey data makes causal inference problematic. The relationships reported in this manuscript are mere associations. Nonetheless, given the strength of the associations, the programmatic implications are justified.

\section{Conclusion}

Overall, the findings of this study indicate that some social groups may benefit from underweight control measures while others require overweight reduction strategies. Nonetheless, focusing on either of these weight abnormalities may jeopardize program effectiveness. Overweight prevention interventions will need to be designed and implemented concomitantly with underweight prevention programs. Indeed, a comprehensive approach is indicated with interventions addressing the dual burden of overweight and underweight and implemented at the individual, organizational, community and policy levels.

Strategic communication programs should be an important component of this comprehensive approach to weight control programming. The aim should be to promote a healthy balance between energy intake and energy expenditure. Such interventions should seek to increase understanding about healthy diets and lifestyles to avoid underweight and overweight, promote physical exercise and encourage people to consume more wholesome foods. The strategic communication interventions should use a multi-media approach to target multiple audience groups across the life stages with nutrition education, culturally appropriate messages about ideal body weight and information about healthy ways of expending energy. Given the important role of ethnicity and selected characteristics of the cluster of residence, community mobilization efforts that engage community groups and leadership and are aimed at changing unhealthy community norms underlying weight abnormalities, will play a key role in these efforts. Through forums ranging from small group meetings to communitywide events, residents should be able to learn about the health risks associated with prevalent lifestyles, preferred and normative body images, common foods and eating patterns. Through community meetings and events, participants should also be able to learn how to prepare staple foods in a way that meals are both healthy and tasty. Community-level interventions would not be complete without addressing the factors that facilitate access to cheap, high-energy, high-fat foods in the community. Indeed, in both urban and rural Nigeria, vendors of prepared energy-dense street food are ubiquitous (Akinbode et al., 20II, Dipeolu et al., 2007, Olutayo and Akanle, 2009). These vendors tend to privilege visual appeal and taste over nutritional value and safety (Dipeolu et al., 2007, Umoh and Odoba, 1999). In this respect, efforts aimed at educating vendors of prepared meals in the communities about how to balance nutrition and flavor while protecting consumer safety are relevant.

Finally, it is necessary for the Nigerian government to enforce policies to regulate the importation and social marketing of unhealthy foods and drinks. The food industry should be held 
accountable. Steps should be taken to ban refined, imported foods that are rich in sugars and saturated fats. In contrast, the government should take steps to make locally grown and nutritive food items accessible to women. The newly launched Agriculture Promotion Policy in Nigeria is a commendable effort in the right direction (Federal Ministry of Agriculture \& Rural Development (FMARD), 2016). This policy is ambitious and aims to reverse the trade deficits due to food imports. It is obvious that concerted multisectoral efforts are needed to achieve this goal.

\section{References}

ADEGBOYE, O. R., SMITH, C., ANANG, D. \& MUSA, H. 2015. Comparing and Contrasting Three Cultural Food Customs from Nigeria and Analyzing the Nutrient Content of Diets from These Cultures with the Aim of Proffering Nutritional Intervention. Critical reviews in food science and nutrition, 00-00.

AKINBODE, S., DIPEOLU, A. \& OKUNEYE, P. 20II. Willingness to pay for street food safety in Ogun state, Nigeria. Journal of Agricultural \& Food Information, 12, I54-166.

ASFAW, A. 2006. The effects of obesity on doctordiagnosed chronic diseases in Africa: empirical results from Senegal and South Africa. Journal of public health policy, 27, 250-264.

BELLO, S. I., OJIEABU, W. A. \& BELLO, I. K. 2016. Prevalence of Hypertension Among Fulani Herdsmen in Rural Community of Nigeria. Bangladesh Journal of Medicine, 27, 48-54.

BENKESER, R., BIRITWUM, R. \& HILL, A. 2012. Prevalence of overweight and obesity and perception of healthy and desirable body size in urban, Ghanaian women. Ghana medical journal, 46, 66-75.

BHARATI, S., PAL, M., BHATTACHARYA, B. \& BHARATI, P. 2007. Prevalence and causes of chronic energy deficiency and obesity in Indian women. Human Biology, 395-4I 2.

BIDER-CANFIELD, Z., MARTINEZ, M., WANG, X., YU, W., BAUTISTA, M., BROOKEY, J., PAGE, K., BUCHANAN, T. \& XIANG, A. 2016. Maternal obesity, gestational diabetes, breastfeeding and childhood overweight at age 2 years. Pediatric obesity.

BLACK, R. E., ALLEN, L. H., BHUTTA, Z. A., CAULFIELD, L. E., DE ONIS, M., EZZATI, M., MATHERS, C., RIVERA, J., MATERNAL \& GROUP, C. U. S. 2008. Maternal and child undernutrition: global and regional exposures and health consequences. The lancet, 37I, 243-260.

BONEY, C. M., VERMA, A., TUCKER, R. \& VOHR, B. R. 2005. Metabolic syndrome in childhood: association with birth weight, maternal obesity, and gestational diabetes mellitus. Pediatrics, II5, e290-e296.

BOUZITOU, G. D. N., FAYOMI, B. \& DELISLE, H. 2005. Malnutrition infantile et surpoids maternel dans des ménages urbains paurres au Bénin. Cahiers d'études et de recherches francophones/Santé, I5, 263-270.

CALLAWAY, L. K., PRINS, J. B., CHANG, A. M. \& MCINTYRE, H. D. 2006. The prevalence and impact of overweight and obesity in an Australian obstetric population. Medical Journal of Australia, I84, 56.

CAPPUCCIO, F. P., KERRY, S. M., ADEYEMO, A., LUKE, A., AMOAH, A. G., BOVET, P., CONNOR, M. D., FORRESTER, T., GERVASONI, J.-P. \& KAKI, G. K. 2008. Body size and blood pressure: an analysis of Africans and the African diaspora. Epidemiology (Cambridge, Mass.), 19, 38.

CEDERGREN, M. I. 2004. Maternal morbid obesity and the risk of adverse pregnancy outcome. Obstetrics \& Gynecology, I03, 219-224.

COHEN, E., BOETSCH, G., PALSTRA, F. \& PASQUET, P. 2013. Social valorisation of stoutness as a determinant of obesity in the context of nutritional transition in Cameroon: the Bamileke case. Social Science \& Medicine, 96, 2432.

CRESSWELL, J. A., CAMPBELL, O. M., DE SILVA, M. J. \& FILIPPI, V. 20I2. Effect of maternal obesity on neonatal death in sub-Saharan Africa: multivariable analysis of 27 national datasets. The Lancet, 380, I325- I 330.

DICKSON, R., AWASTHI, S., WILLIAMSON, P., DEMELLWEEK, C. \& GARNER, P. 2000. Effects of treatment for intestinal helminth infection on growth and cognitive performance in children: systematic review of randomised trials. Bmj, 320, I697-I70I.

DIOP, S., SAUVAIN-DUGERDIL, C., DIARRA, S. \& DOUPTCHEVA, N. 20I4. La montée de l'obésité dans un contexte où la dénutrition n'est pas éradiquée. Application de l'approche des Capabilités sur des données mixtes au Mali. Etude de la Population Africaine, 28, 776.

DIPEOLU, O., AKINBODE, O. \& OKUNEYE, A. 2007. Income generating potentials of street food vending businesses in Ogun State, Nigeria. ASSET: An International Journal (Series C)\}, 2, I80-I89.

DOAK, C. 2002. Large-scale interventions and programmes addressing nutrition-related chronic diseases and obesity: examples from 14 countries. Public Health Nutrition, 5, 275-277. 
FEDERAL MINISTRY OF AGRICULTURE \& RURAL DEVELOPMENT (FMARD) 20I6. The Agriculture Promotion Policy - 2016-2020. Abuja Nlgeria.

FEZEU, L., MINKOULOU, E., BALKAU, B., KENGNE, A.-P., AWAH, P., UNWIN, N., ALBERTI, G. K. \& MBANYA, J.-C. 2006. Association between socioeconomic status and adiposity in urban Cameroon. International journal of epidemiology, 35, I05-III.

GARTNER, A., MAIRE, B., TRAISSAC, P., MASSAMBA, J. P., KAMELI, Y., KERAUDREN, V. \& DELPEUCH, F. 2000. Sensitivity and specificity of the body mass index to assess low percent body fat in African women. American Journal of Human Biology, I2, 25-3I.

GLEW, R. H., CONN, C. A., VANDERJAGT, T. A., CALVIN, C. D., OBADOFIN, M. O., CROSSEY, M. \& VANDERJAGT, D. J. 2004. Risk factors for cardiovascular disease and diet of urban and rural dwellers in northern Nigeria. Journal of Health, Population and Nutrition, 357-369.

GLEW, R. H., WILLIAMS, M., CONN, C. A., CADENA, S. M., CROSSEY, M., OKOLO, S. N. \& VANDERJAGT, D. J. 200I. Cardiovascular disease risk factors and diet of Fulani pastoralists of northern Nigeria. The American journal of clinical nutrition, 74, 730-736.

HAN, Z., MULLA, S., BEYENE, J., LIAO, G. \& MCDONALD, S. D. 20II. Maternal underweight and the risk of preterm birth and low birth weight: a systematic review and meta-analyses. International journal of epidemiology, 40, 65-I0I.

HOLDSWORTH, M., GARTNER, A., LANDAIS, E., MAIRE, B. \& DELPEUCH, F. 2004. Perceptions of healthy and desirable body size in urban Senegalese women. International journal of obesity, 28, I56I-I568.

KANDALA, N.-B. \& EMINA, J. B. 2016. THE DUAL BURDEN OF NUTRITION TRANSITION AMONG WOMEN IN SUB-SAHARAN AFRICA: A CASE STUDY OF UNDERWEIGHT IN NIGERIA. Journal of Biosocial Science, 48, 486501.

KAPLAN, M. S., HUGUET, N., NEWSOM, J. T., MCFARLAND, B. H. \& LINDSAY, J. 2003. Prevalence and correlates of overweight and obesity among older adults: findings from the Canadian National Population Health Survey. The Journals of Gerontology Series A: Biological Sciences and Medical Sciences, 58, MI018MI030.

KEDING, G. B., MSUYA, J. M., MAASS, B. L. \& KRAWINKEL, M. B. 20I3. Obesity as a public health problem among adult women in rural Tanzania. Global Health: Science and Practice, I, 359-37I.
KIM, S., STEIN, A. \& MARTORELL, R. 2007a. Country development and the association between parity and overweight. International journal of obesity, 3I, 805-8I2.

KIM, S. A., YOUNT, K. M., RAMAKRISHNAN, U. \& MARTORELL, R. 2007b. The relationship between parity and overweight varies with household wealth and national development. International journal of epidemiology, 36, 93-I0I.

KRISHNAMOORTHY, U., SCHRAM, C. \& HILL, S. 2006. Review article: Maternal obesity in pregnancy: is it time for meaningful research to inform preventive and management strategies? BJOG: An International Journal of Obstetrics \& Gynaecology, I I 3, I I 34- I I 40.

LESLIE, J. 1991. Women's nutrition: the key to improving family health in developing countries? Health Policy and Planning, 6, I-19.

LINDSAY, K., GIBNEY, E. \& MCAULIFFE, F. 2012. Maternal nutrition among women from SubSaharan Africa, with a focus on Nigeria, and potential implications for pregnancy outcomes among immigrant populations in developed countries. Journal of human nutrition and dietetics, 25, 534-546.

LOPEZ-ARANA, S., BURDORF, A. \& AVENDANO, M. 2013. Trends in overweight by educational level in 33 low-and middle-income countries: the role of parity, age at first birth and breastfeeding. Obesity Reviews, I4, 806-8I7.

MENDEZ, M. A., MONTEIRO, C. A. \& POPKIN, B. M. 2005. Overweight exceeds underweight among women in most developing countries. The American journal of clinical nutrition, 8I, 7|4-72I.

MERCHANT, K. \& MARTORELL, R. I987. Frequent reproductive cycling: does it lead to nutritional depletion of mothers? Progress in food \& nutrition science, 12, 339-369.

MILNER, K., GREYLING, M., GOETZEL, R., DA SILVA, R., KOLBE-ALEXANDER, T., PATEL, D., NOSSEL, C. \& BECKOWSKI, M. 20I5. The relationship between leadership support, workplace health promotion and employee wellbeing in South Africa. Health promotion international, 30, 5|4-522.

MORAGIANNI, V. A., JONES, S.-M. L. \& RYLEY, D. A. 2012. The effect of body mass index on the outcomes of first assisted reproductive technology cycles. Fertility and sterility, 98, 102-108.

MÜLLER, O. \& KRAWINKEL, M. 2005. Malnutrition and health in developing countries. Canadian Medical Association Journal, I73, 279-286.

OLUTAYO, A. \& AKANLE, O. 2009. Fast food in Ibadan: an emerging consumption pattern. Africa, 79, 207-227. 
POPKIN, B. M. \& NIELSEN, S. J. 2003. The sweetening of the world's diet. Obesity research, II, I325-I332.

PRENTICE, A. M. \& JEBB, S. A. 200I. Beyond body mass index. Obesity reviews, 2, |4|-| 47.

REDDY, S., RESNICOW, K., JAMES, S., KAMBARAN, N., OMARDIEN, R. \& MBEWU, A. 2009. Underweight, overweight and obesity among South African adolescents: results of the 2002 National Youth Risk Behaviour Survey. Public health nutrition, 12, 203-207.

ROMERO-CORRAL, A., SOMERS, V. K., SIERRAJOHNSON, J., THOMAS, R. J., COLLAZOCLAVELL, M., KORINEK, J., ALLISON, T. G., BATSIS, J., SERT-KUNIYOSHI, F. \& LOPEZJIMENEZ, F. 2008. Accuracy of body mass index in diagnosing obesity in the adult general population. International journal of obesity, 32, 959-966.

ROTIMI, C., OKOSUN, I., JOHNSON, L., OWOAJE, E., LAWOYIN, T., ASUZU, M., KAUFMAN, J., ADEYEMO, A. \& COOPER, R. 1999. The distribution and mortality impact of chronic energy deficiency among adult Nigerian men and women. European journal of clinical nutrition, 53, 734-739.

SCHMIDHUBER, J. \& SHETTY, P. 2005. Nutrition transition, obesity and noncommunicable diseases: drivers, outlook and concerns. SCN News, 29, 13-19.

SEBIRE, N., JOLLY, M., HARRIS, J., REGAN, L. \& ROBINSON, S. 200I. Is maternal underweight really a risk factor for adverse pregnancy outcome? A population-based study in London. British Journal of Obstetrics and Gynaecology, I08, 6I-66.

SMITH, S. A., HULSEY, T. \& GOODNIGHT, W. 2008. Effects of obesity on pregnancy. Journal of Obstetric, Gynecologic, \& Neonatal Nursing, 37, I76-184.

TELLER, C. H. \& YIMER, G. 20I5. Levels and determinants of malnutrition in adolescent and adult women in Southern Ethiopia. Ethiopian Journal of Health Development, 14, 57-66.

UDJO, E. O. \& LALTHAPERSAD-PILLAY, P. 2014. Mortality from non-communicable diseases in South Africa, 1997-2009. Etude de la Population Africaine, 28, 60I.

$\mathrm{UMOH}$, V. \& ODOBA, M. 1999. Safety and quality evaluation of street foods sold in Zaria, Nigeria. Food Control, 10, 9-14.

UTHMAN, O. A. 2009. Patterns, distribution, and determinants of under-and overnutrition among women in Nigeria: a population-based analysis. Journal of Public Health, I7, 289-299.

UTHMAN, O. A. \& AREMU, O. 2008. Malnutrition among women in sub-Saharan Africa: rural-urban disparity. Rural and remote health, 8.

VAN DER SANDE, M. A., CEESAY, S. M., MILLIGAN, P. J., NYAN, O. A., BANYA, W. A., PRENTICE, A., MCADAM, K. P. \& WALRAVEN, G. E. 200I. Obesity and undernutrition and cardiovascular risk factors in rural and urban Gambian communities. American Journal of Public Health, 9I, 164I-1644.

VAN DER STEEG, J. W., STEURES, P., EIJKEMANS, M. J., HABBEMA, J. D. F., HOMPES, P. G., BURGGRAAFF, J. M., OOSTERHUIS, G. J. E., BOSSUYT, P. M., VAN DER VEEN, F. \& MOL, B. W. 2008. Obesity affects spontaneous pregnancy chances in subfertile, ovulatory women. Human Reproduction, 23, 324-328.

WEISS, J. L., MALONE, F. D., EMIG, D., BALL, R. H., NYBERG, D. A., COMSTOCK, C. H., SAADE, G., EDDLEMAN, K., CARTER, S. M. \& CRAIGO, S. D. 2004. Obesity, obstetric complications and cesarean delivery rate-a population-based screening study. American journal of obstetrics and gynecology, 190, I091-1097.

WEN, W., GAO, Y., SHU, X., YANG, G., LI, H., JIN, F. \& ZHENG, W. 2003. Sociodemographic, behavioral, and reproductive factors associated with weight gain in Chinese women. International journal of obesity, 27, 933-940.

WITKOWSKI, T. H. 2007. Food marketing and obesity in developing countries: analysis, ethics, and public policy. Journal of Macromarketing, 27, I26-। 37.

WORLD HEALTH ORGANIZATION (WHO) 2000. Obesity: preventing and managing the global epidemic. World Health Organization Technical Report Series, 894:i-xii, 1-253.

YILMAZ, N., KILIC, S., KANAT-PEKTAS, M., GULERMAN, C. \& MOLLAMAHMUTOGLU, L. 2009. The relationship between obesity and fecundity. Journal of Women's Health, 18, 633636.

ZARGAR, A., MASOODI, S., LAWAY, B., KHAN, A., WANI, A., BASHIR, M. \& AKHTAR, S. 2000. Prevalence of obesity in adults--an epidemiological study from Kashmir Valley of Indian Subcontinent. The Journal of the Association of Physicians of India, 48, II 70-I I 74.

ZIRABA, A. K., FOTSO, J. C. \& OCHAKO, R. 2009. Overweight and obesity in urban Africa: A problem of the rich or the poor? BMC public health, 9, I. 